\title{
Clinton prepares to sign biodiversity treaty to celebrate Earth Day
}

Washington. US President Bill Clinton is expected in the next few days to announce his intention to sign the international agreement on biodiversity protection that former president George Bush rejected at last June's Earth summit in Rio de Janeiro. The announcement may come as part of a package of environmental initiatives to be unveiled on 22 April to celebrate Earth Day.

The Bush administration said that it was opposed to the treaty on the basis of ambiguous language about ownership of patent rights for products derived from indigenous plants and animals. It is not clear whether companies would be forced to share the rights with or even transfer them to the countries that owned the biological resources. Bush said that such a policy would be harmful to US biotechnology and pharmaceutical companies.

Several companies that sided with the Bush administration at the time have since withdrawn their opposition to the treaty, saying that they were pressured into supporting the decision without having studied the issue thoroughly. Bush's concern about intellectual property rights is believed to have been a smokescreen: a more important reason was the one given by the sincedisbanded White House Council on Competitiveness, which was concerned that increased protection for endangered species would make it harder for US companies to operate at home and abroad.

However, even those who favour the treaty admit that serious problems remain over what Richard Mott of the World Wildlife Fund calls the "inartfully and ambiguously drafted" convention. In one paragraph, the treaty seems to provide for "the adequate and effective protection of intellectual property rights", while elsewhere it implies that signatory countries - and private companies within those countries - would have to share whatever technology is derived from native biological resources.

Another point of controversy is the implication within the convention that wealthy developed nations would be required to make fixed payments, rather than voluntary contributions, to developing countries for biodiversity protection programmes. A related matter is how those funds would be distributed.

In recent months, a coalition including Genentech and Merck and Co., along with the World Wildlife Fund and the World Resources Institute, have been discussing with the White House ways for the United States to sign the convention without sacrificing intellectual property rights. Their solution is for the United States to attach a rider clarifying its interpretation of any controversial provisions. "Vagueness can be your worst enemy or your best friend", says Ray Briscuso of the Industrial Biotechnology Association, which originally opposed

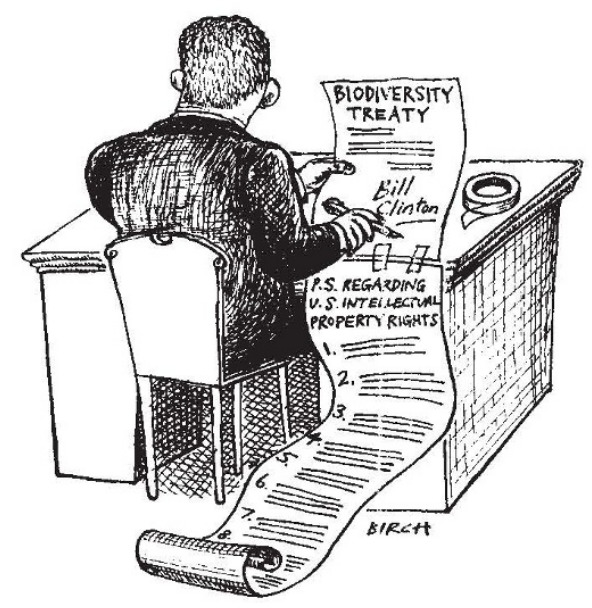

the treaty but now supports attaching a clarification to the president's signature.

The European Communities (EC) also signed the biodiversity convention at Rio but remain concerned about the intellectual property rights issue, and a similar rider spelling out its interpretation is expected to accompany ratification. Fourteen countries have already ratified the treaty, almost half of the 30 needed to bring it into force.

EC environmental officials last week met

Vice President Al Gore and his staff in Washington, where they discussed the biodiversity convention as well as European plans for a carbon tax and Clinton's proposed energy tax as methods of reducing worldwide emissions of greenhouse gases. Tougher worldwide restrictions on greenhouse gases are among the international environmental matters under review by the White House National Security Council. The review, which began in March, includes wetlands, oceans, trade, population and sustainable development.

Of all the international issues on the table, signing the biodiversity accord was seen as one of the easiest to solve. "I think Clinton wants to do something notable [for Earth Day], and that's a very likely candidate", says Mott.

Even if the United States signs the convention before the one-year deadline in early June, it is not clear what it must do to conserve its biological resources. The treaty is vague about the need for signatories to protect their own biodiversity.

A presidential announcement would reflect the convention's value as a symbolic step towards preserving global biodiversity. What will really make a difference are protocols established after the biodiversity convention comes into force that are similar to the 1987 Montreal Protocol restricting the use of chlorofluorocarbons to protect ozone. "Anything with teeth is going to be in the protocols", says Barbara Bramble of the National Wildlife Federation.

Tony Reichhardt

\section{Synergen trims sails to survive}

Washington. The US biotechnology company Synergen Inc., reeling from disappointing clinical results that have driven down the price of its stock by more than two-thirds, last week replaced its chief executive and reorganized management.

Board chairman and company co-founder Larry Soll has replaced Jon Saxe as chief executive officer and four executive vice presidents will share the duties of president, a post also held by Saxe, as the company, based in Boulder, Colorado, tries to recover from recent poor results of trials of its antisepsis drug Antril. Michael Catalano, vice president of clinical research, will become a technical consultant to the company. Synergen plans a second phase-III trial with Antril, an interleukin- 1 antagonist, that will focus on "seriously ill" patients in the hope of showing more dramatic gains.

One silver lining for Synergen is its $\$ 220$ million in capital, which will allow it to conduct a follow-up trial with Antril as well as to pursue plans to market the drug in Europe and to begin joint trials with Syntex on a drug to treat amyotrophic lateral sclerosis, or Lou Gehrig's disease. A spokesman says that the company may save money by terminating some research, for example work on an elastase inhibitor for cystic fibrosis.

Synergen believes that data showing a reduction of 22 per cent in mortality for the subset of most critically ill sepsis patients is sufficient basis for a licence in Europe, although mortality for the entire patient population tested was not significantly different from placebo control rates. With no other products likely to be ready before the late 1990s, Synergen's best bet may be to use its capital to buy a smaller company needing money to develop a product that is closer to market.

Jenna Roberts 